\title{
Mangrove Leaf Herbivory along a Hydrocarbon Pollution Gradient in a Mangrove Forest (Rhizophora racemosa) in the Niger River Delta, Nigeria
}

\author{
Aroloye O Numbere ${ }^{1,2 *}$ and Gerardo R Camilo ${ }^{1}$ \\ ${ }^{1}$ Department of Biology, Saint Louis University, St Louis, Missouri, USA; ${ }^{2}$ Department of Animal and Environmental Biology, University \\ of Port Harcourt, Choba, Nigeria
}

\begin{abstract}
This study was done to test the palatability of leaves of mangroves growing in a highly and lowly polluted environment. We hypothesized that bottom-up transfer of pollutants from soil to leaves would influence herbivory due to the toxic effect of pollution. Exclusion experiment was done to test for leave herbivory in lowly and highly polluted plots while cafeteria experiment was done to determine the feeding preference of 20 West African red mangrove crabs (Goniopsis pelii). In the first experiment a total of 453 mangrove leaves were sampled for six months, one year and two years. Results indicate that there was significant difference in herbivory between highly and lowly polluted treatment in the six months $(\mathrm{F} 2,160=3.33, \mathrm{P}=0.04)$, one year $(\mathrm{F} 2,184=1.90, \mathrm{P}=0.02)$ and two years ( $\mathrm{F} 1,169=7.58, \mathrm{P}=0.01$ ) samples. There was more leave herbivory in highly than in lowly polluted plot. The pattern of incisions indicates that crab herbivory was the highest (53\%) followed by insects (25\%) and undetermined (22\%). In the laboratorybased experiment, there was significant difference in leave incisions from both plots $(\mathrm{P}=0.01)$ with more leaves from highly polluted plot consumed $(4,521.69 \mathrm{~cm} 2)$ than leaves from lowly polluted plot $(2,769.83 \mathrm{~cm} 2)$. This implies that hydrocarbon pollution influenced leaf herbivory.
\end{abstract}

Keywords: Cafeteria experiment; Exclusion experiment; Goniopsis pelii; Herbivory; Hydrocarbon pollution; Crab

\section{INTRODUCTION}

Herbivory is the act of feeding on the tissues or internal fluids of living plants or algae [1]. Herbivory changes the physical and chemical traits of plants [2], which may have ripple effect on the food chain. Insects are the most destructive herbivores [3,4], and show greater presence in higher latitudes [5] such as tropical areas e.g., Africa. Leaf herbivory is higher in nutrient rich sites and amongst younger leaves [6]. Younger leaves have higher herbivory because they have higher photosynthetic ability than older leaves. Insect incision on premature leaves cause the loss of apical buds, lowers productivity and changes plant architecture [7,8]. Insect herbivory causes defoliation, which reduces the survival potential of mangroves [9]. Wood-boring moths and beetles create tunnels through leaves of mangroves [10]. A species of mangrove called Kandelia obovata had reduced life span as a result of leaf damage [11]. Similarly, consumer activities of herbivores impact the structure of plant communities and influence species succession [12]. Succession occurs when herbivory alters the regional differences in plant diversity [4].
Crabs, on the other hand, are a major herbivore of mangroves. This is because their predation of mangrove propagules affects natural regeneration and species distribution across intertidal zones [13]. Crabs form obligatory relationship with mangroves for survival [14]. Grabsidae, a family of crabs, in the Indo-west Pacific region live and forage directly on mangrove trees [13]. Similarly, Sesarma leptosome of East Africa is an active climber, and feed on mangrove materials [15]. However, crab preference for mangrove depends on the age [16], and nutritional value of the tree $[17,18]$. Mangrove leaves are nutritious; and influence the survival, growth and reproduction of crabs [15].

Hydrocarbon pollution therefore, affects plant resistance and makes it vulnerable to herbivore attack [19]. Plants growing in polluted soil may have more damage- tolerance than plants growing in non-polluted soil [12]. Leaves from polluted soil can become unpalatable for herbivores when pollutants lodge in the leaves [20]. But, high concentration of crude oil can out rightly kill mangrove fauna and flora [21], which affects nutrient cycle [22] and leaf production in mangroves. These situations reduce the ability of mangroves to resist herbivore attack [23]. Crude oil can also act as

Correspondence to: Aroloye O Numbere, Department of Animal and Environmental Biology, University of Port Harcourt, Choba, Nigeria, Tel:+2348056002989; E-mail: aroloyen@yahoo.com

Received: March 28, 2019, Accepted: April 18, 2019, Published: April 29, 2019

Citation: Numbere AO, Camilo GR (2019) Mangrove Leaf Herbivory along aHydrocarbon Pollution Gradient in a Mangrove Forest (Rhizophora racemosa) in the Niger River Delta, Nigeria. J Pet Environ Biotechnol 10: 391. doi: 10.35248/2157-7463.19.10.391

Copyright: (C) 2019 Numbere AO, et al. This is an open-access article distributed under the terms of the Creative Commons Attribution License, which permits unrestricted use, distribution, and reproduction in any medium, provided the original author and source are credited. 
antiseptic and destroy parasites [24], leading to the enhancement of growth in mangroves [20].

The goal of this study, therefore, was to firstly compare herbivory in highly and lowly polluted treatments (exclusion), and secondly to compare the feeding preference of crabs of leaves from highly and lowly polluted plots (cafeteria experiment). We specifically selected the red mangrove leaves (Rhizophora species) because they are the most dominant and most palatable species in the study area. The objective of the study is therefore: (1) To determine leaf herbivory in excluded and control mangrove branches, (2) to determine leaf herbivory in upper and lower mangrove branches, (3) to determine leaf herbivory in highly and lowly polluted mangrove forest.

\section{MATERIALS AND METHODS}

\section{Study area}

This study was conducted in a mangrove forest in Okrika, located near a major refinery in the southern part of Nigeria known as the Niger River Delta (Figure 1). This refinery is a major outlet for exportation of crude oil out of Nigeria. The climate is tropical monsoon with rainfall occurring all throughout the year except in December, January and February. The mean annual precipitation ranges from 2500-4500 $\mathrm{mm}$ [25]. The mean annual temperature ranges from $26^{\circ} \mathrm{C}-30^{\circ} \mathrm{C}$. The soil is swampy and grades from red to brown, while the soil $\mathrm{pH}$ ranges from acidic to neutral i.e., 6.106.53 (Table 1). The soil is more acidic than alkaline because of the ammonia and methane gases produced through decomposition of plant matter. Its mangrove forest is uniquely divided into two sections by a tarred road ( $\sim 5 \mathrm{~m}$ wide). Running parallel to the road and about $1 \mathrm{~m}$ apart are ten sets of giant nickel/steel alloy-plated crude oil pipelines ( $\sim$ diameter 8-10 inches) that convey crude oil and petroleum products from the refinery to the jetty. These two features created an artificial partitioning of the mangrove forest into two sections of highly and lowly polluted plots that are $20 \mathrm{~m}$ and $40 \mathrm{~m}$ away from the crude oil pipelines respectively. The average total hydrocarbon content of the lowly polluted plot is $344.1 \mathrm{mg} / \mathrm{l}$ while the average THC of the highly polluted plot is $2361.3 \mathrm{mg} / \mathrm{l}$. The THC of the highly polluted plot is higher because of higher crude oil spillages recorded in this area. This delineation is further validated by an earlier studies carried out in the area [26,27].

\section{Study species}

Rhizophora racemosa Meyer (Rhizophoracea), known as red mangroves, are the most dominant species in the study area $[28,29]$. These mangroves survive hyper saline conditions and are widespread in the estuarine wetlands of the Niger Delta $[30,31]$ and the Atlantic [32]. Rhizophora species have the largest propagule size (i.e., $12-21 \mathrm{~cm}$ ) when compared to other species such as black and white mangroves. The leaves and propagules of the red mangroves are a delicacy for crabs, fish and other herbivores because of their nutritive value.

The West African Red Mangrove crabs (Goniopsis pelii) inhabit mangrove forests in the Niger River Delta, and parts of the Atlantic coast. For the purpose of our study the crabs are grouped into three sizes namely: small (length: $5-6 \mathrm{~cm}$; width: $4-5 \mathrm{~cm}$ ), medium (length: 7-8 cm; width: $4-6 \mathrm{~cm}$ ) and large (length: $8-10 \mathrm{~cm}$; width: $5-6 \mathrm{~cm}$ ). This species of crabs are the most dominant in the red mangrove forests (Rhizophora species), and have a black, white and orange color on their dorsal, ventral and limb regions respectively. They are decapods with five pairs of limbs, four hairy (pelii) and one non-hairy (chelipads). The chelipads have sharp edges for shredding the leaves and propagules of mangroves.

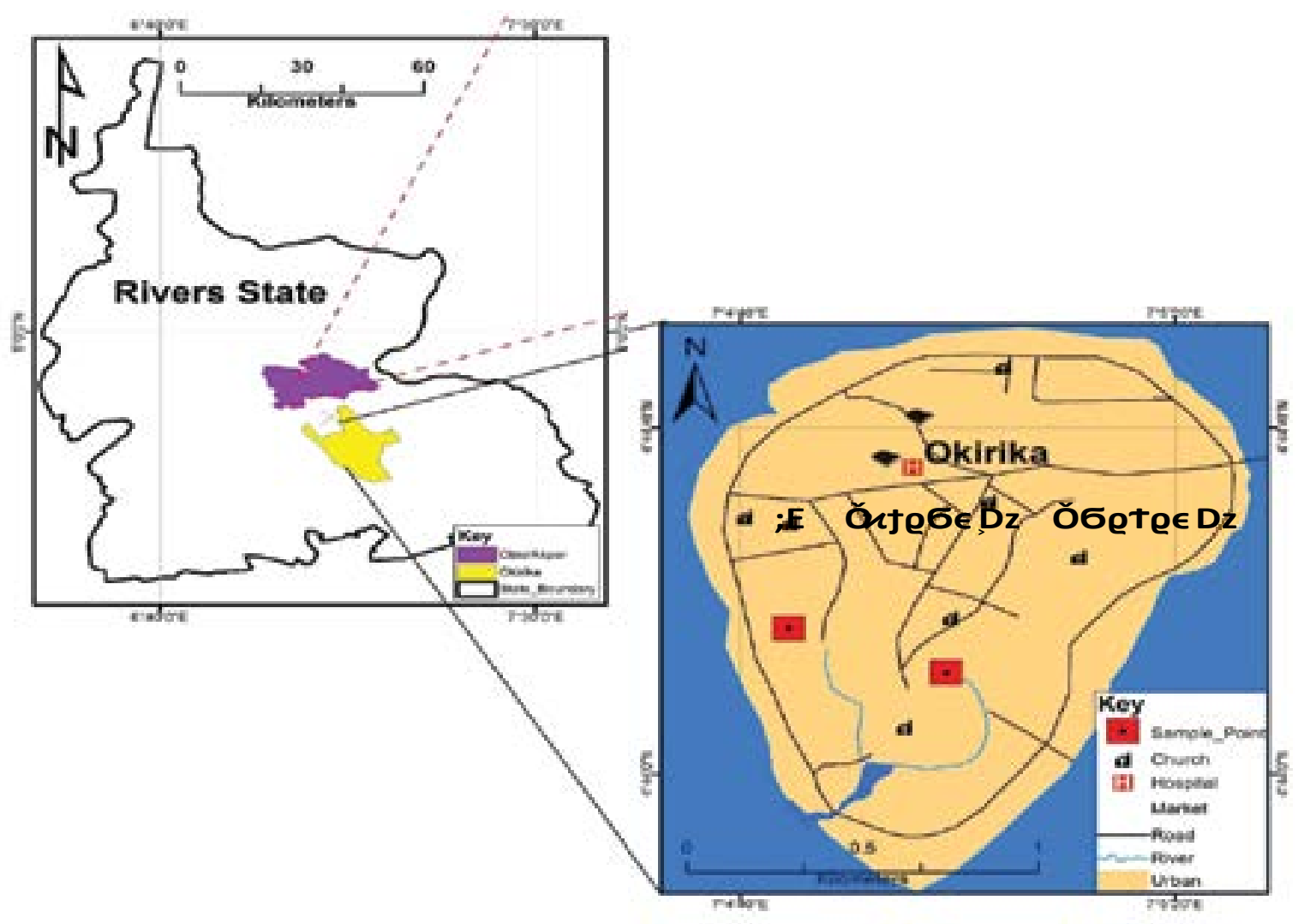

Figure 1: Map of study area indicating the area where herbivory experiment was conducted in Okrika, Niger Delta, Nigeria. 


\begin{tabular}{|c|c|c|c|c|c|c|c|c|c|c|c|c|c|c|}
\hline $\begin{array}{l}\text { Study } \\
\text { location }\end{array}$ & $\begin{array}{l}\text { Conduct. } \mu \mathrm{s} / \\
\mathrm{cm}\end{array}$ & $\mathrm{pH}$ & TOC (\%) & $P(\mathrm{mg} /)$ & $\begin{array}{l}\mathrm{SO}_{4}{ }^{2-} \\
(\mathrm{mg} / \mathrm{l})\end{array}$ & $\begin{array}{c}\mathrm{Cd} \\
(\mathrm{mg} / \mathrm{l})\end{array}$ & $\mathrm{Pb}(\mathrm{mg} / \mathrm{l})$ & $\mathrm{Zn}(\mathrm{mg} / \mathrm{l})$ & $\begin{array}{c}\mathrm{Cu} \\
(\mathrm{mg} / \mathrm{l})\end{array}$ & $M n(m g / l)$ & $\mathrm{Ca}(\mathrm{mg} / \mathrm{l})$ & K (mg/l) & $M g(m g / l)$ & $\mathrm{THC}(\mathrm{mg} / \mathrm{l})$ \\
\hline OK1 & 1133 & 5.94 & 1.989 & 0.07 & 25 & 0.06 & 6.21 & 4.86 & 1.26 & 1.52 & 33.28 & 54.95 & 229.48 & 2682 \\
\hline OK2 & 783 & 6.4 & 1.716 & 0.03 & 28 & 0.001 & 0.001 & 1.26 & 0.001 & 0.44 & 45.17 & 38.31 & 143.73 & 2155 \\
\hline OK3 & 9920 & 5.97 & 3.315 & 0.09 & 60 & 0.001 & 0.001 & 2.6 & 0.001 & 4.71 & 36.95 & 334.8 & 513.2 & 2247 \\
\hline Mean & 3945.33 & 6.10 & 2.34 & 0.06 & 37.67 & 0.02 & 2.07 & 2.91 & 0.42 & 2.22 & 38.47 & 142.69 & 295.47 & 2361.33 \\
\hline SD & 5177.172 & 0.257 & 0.855 & 0.0306 & 19.399 & 0.034 & 3.5848 & 1.8195 & 0.727 & 2.2202 & 6.0884 & 166.583 & 193.373 & 281.490 \\
\hline SE & 2989.042 & 0.147 & 0.494 & 0.0176 & 11.200 & 0.019 & 2.0697 & 1.0505 & 0.419 & 1.2818 & 3.5151 & 96.177 & 111.64 & 162.518 \\
\hline
\end{tabular}

Table 1A: Soil physico-chemistry of mangrove soil in highly polluted plot in mangrove forest in the Niger Delta, Nigeria.

\begin{tabular}{|c|c|c|c|c|c|c|c|c|c|c|c|c|c|c|}
\hline $\begin{array}{l}\text { Study } \\
\text { location }\end{array}$ & $\begin{array}{l}\text { Conduct. } \\
\mu \mathrm{s} / \mathrm{cm}\end{array}$ & $\mathrm{pH}$ & $\begin{array}{c}\text { TOC } \\
(\%)\end{array}$ & $\mathrm{P}(\mathrm{mg} / \mathrm{l})$ & $\begin{array}{l}\mathrm{SO}_{4}{ }^{2} \\
(\mathrm{mg} / \mathrm{l})\end{array}$ & $\begin{array}{c}\mathrm{Cd} \\
(\mathrm{mg} / \mathrm{l})\end{array}$ & $\begin{array}{c}\mathrm{Pb} \\
(\mathrm{mg} / \mathrm{l})\end{array}$ & $\begin{array}{c}\mathrm{Zn} \\
(\mathrm{mg} / \mathrm{l})\end{array}$ & $\begin{array}{c}\mathrm{Cu} \\
(\mathrm{mg} / \mathrm{l})\end{array}$ & $\begin{array}{c}\mathrm{Mn} \\
(\mathrm{mg} / \mathrm{l})\end{array}$ & $\begin{array}{c}\mathrm{Ca} \\
(\mathrm{mg} / \mathrm{l})\end{array}$ & $\mathrm{K}(\mathrm{mg} / \mathrm{l})$ & $\begin{array}{c}\mathrm{Mg} \\
(\mathrm{mg} / \mathrm{l})\end{array}$ & $\begin{array}{c}\mathrm{THC} \\
(\mathrm{mg} / \mathrm{l})\end{array}$ \\
\hline BG1 & 308 & 6.53 & 2.81 & 0.15 & 18 & 1.34 & 19.14 & 83.97 & 19.28 & 51.84 & 1149.1 & 133.85 & 737.35 & 434.45 \\
\hline BG2 & 186 & 6.83 & 2.145 & 0.1 & 15 & 0.93 & 22.82 & 88.55 & 38.85 & 62.55 & 1156 & 157.05 & 715.49 & 352.50 \\
\hline BG3 & 19280 & 6.58 & 3.939 & 0.24 & 240 & 0.001 & 0.001 & 8.4 & 0.001 & 4.77 & 282.85 & 407.4 & 794.61 & 245.32 \\
\hline Mean & 6591.33 & 6.65 & 2.96 & 0.16 & 91 & 0.76 & 13.99 & 60.31 & 19.38 & 39.72 & 862.65 & 232.77 & 749.15 & 344.09 \\
\hline SD & 10988.88 & 0.16 & 0.907 & 0.0710 & 129.05 & 0.6861 & 12.251 & 45.011 & 19.425 & 30.738 & 502.133 & 151.681 & 40.89 & 94.845 \\
\hline SE & 6344.431 & 0.09 & 0.524 & 0.0410 & 74.505 & 0.3961 & 7.0732 & 25.987 & 11.215 & 17.746 & 289.907 & 87.573 & 23.590 & 54.759 \\
\hline
\end{tabular}

Table 1B: Soil physico-chemistry of mangrove soil in lowly polluted plot in mangrove forest in the Niger Delta, Nigeria.

\section{Laboratory analysis}

To test for the level of pollution of the mangrove forest soils the total hydrocarbon content (THC) and some physicochemical parameters were determined in the laboratory (Table 1), and include: Cadmium $(\mathrm{Cd})$, Copper $(\mathrm{Cu})$, Zinc $(\mathrm{Zn})$ and Lead $(\mathrm{Pb})$ and nutrient elements namely Calcium (Ca), Magnesium $(\mathrm{Mg})$, Manganese (Mn), Phosphorous (P), Potassium (K), Sulphate $\left(\mathrm{SO}_{3}\right)$ and total organic content (TOC). In the laboratory TOC was analyzed with Wakley Black method [33] while for other metals colorimetric method was applied [34]. THC was analyzed with UV/visible spectrophotometric method ( $420 \mathrm{~nm})$.

\section{Data collection}

Both field-and laboratory-based experiments were conducted in this study. The field-based study was carried out in a mangrove forest situated $1 \mathrm{~km}$ from a refinery, and close to a crude oil evacuation jetty. The oiling activities around the forest it has made it a polluted area, a situation that had made it difficult to find a non-polluted site around the mangrove forest. We thus used previously established study plots [26].

\section{Experimental design}

The experimental design summarizes the experimental activities in the field-based study (Figure 2). Furthermore, Figure 3 illustrates the two major mangrove herbivores, a picture of the exclusion experiment conducted (Figure $3 \mathrm{~d}$ ) and an example of leaf herbivory I mangrove forest (Figures $3 \mathrm{e}$ and $3 \mathrm{~d}$ ).

\section{Exclusion experiment}

Five trees were randomly selected from each plot (i.e., high and low pollution), and geo-referenced with a Garmin GPS (USA) as follows: low ( $04^{\circ}$ 43.497; E $007^{\circ} 05.338$; Elevation: 11.3) and high ( $\mathrm{N} 04^{\circ} 43.512$; E $007^{\circ} 05.266$, Elevation: 11.9). On each tree, opposing branches with three to seven leaves were selected at both upper and lower branches and covered with a nylon wire mesh (Size $<0.05 \mathrm{~m}$ ) (Figure 2d). Experiment was done at both upper and

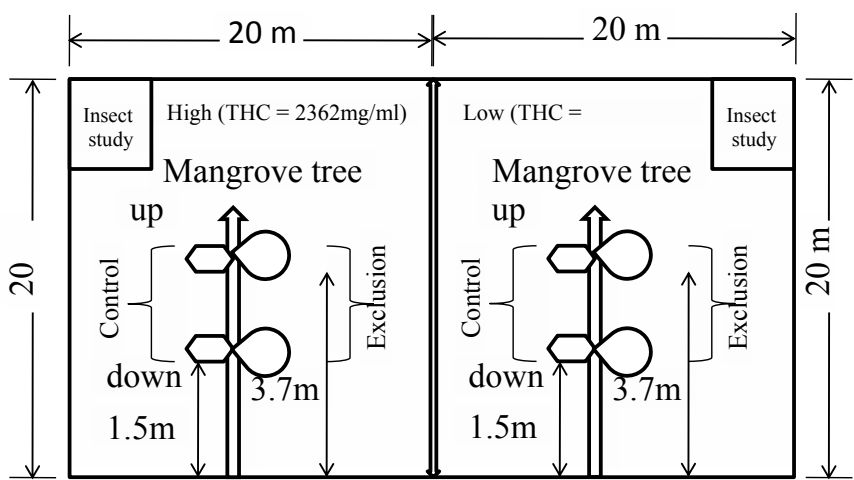

Figure 2: Experimental design of exclusion method used to study herbivory in mangrove forest (Rhizophoracea) in the Niger Delta, Nigeria in highly and lowly polluted plots.

lower branches because there are both lower and upper branch herbivores. The mesh was tied firmly with aluminum ropes to prevent the entry of small insects. The opposite non-excluded branches served as control and were also tagged. At both the upper and lower levels, four exclusions and four controls were established (i.e., eight exclusions and control per tree $\times$ five trees $\times$ six plots) to give a total of 240 samples.

We determined the total herbivory by conducting exclusion experiments in line with previous works [35] for three time intervals: (i) six months; (ii) one year, and (iii) two years. For each study periods the following parameters were investigated: the exclusion effect (i.e., control vs excluded), branch effect (i.e., up vs down) and pollution effect (low vs high). To characterize herbivory, we quantitatively estimated the number of bite marks or incisions made per leave [36], which we interpreted as an attempt to consume the leaves by herbivores.

\section{Cafeteria experiment}

Forty crabs were captured alive by hand using protective gloves. Leave samples were plucked from the mangrove trees or picked from the forest floor and brought to the laboratory for analysis. The captured crabs were placed in four rectangular containers with similar dimensions i.e., length $(35 \mathrm{~cm})$, width $(23 \mathrm{~cm})$ and height 

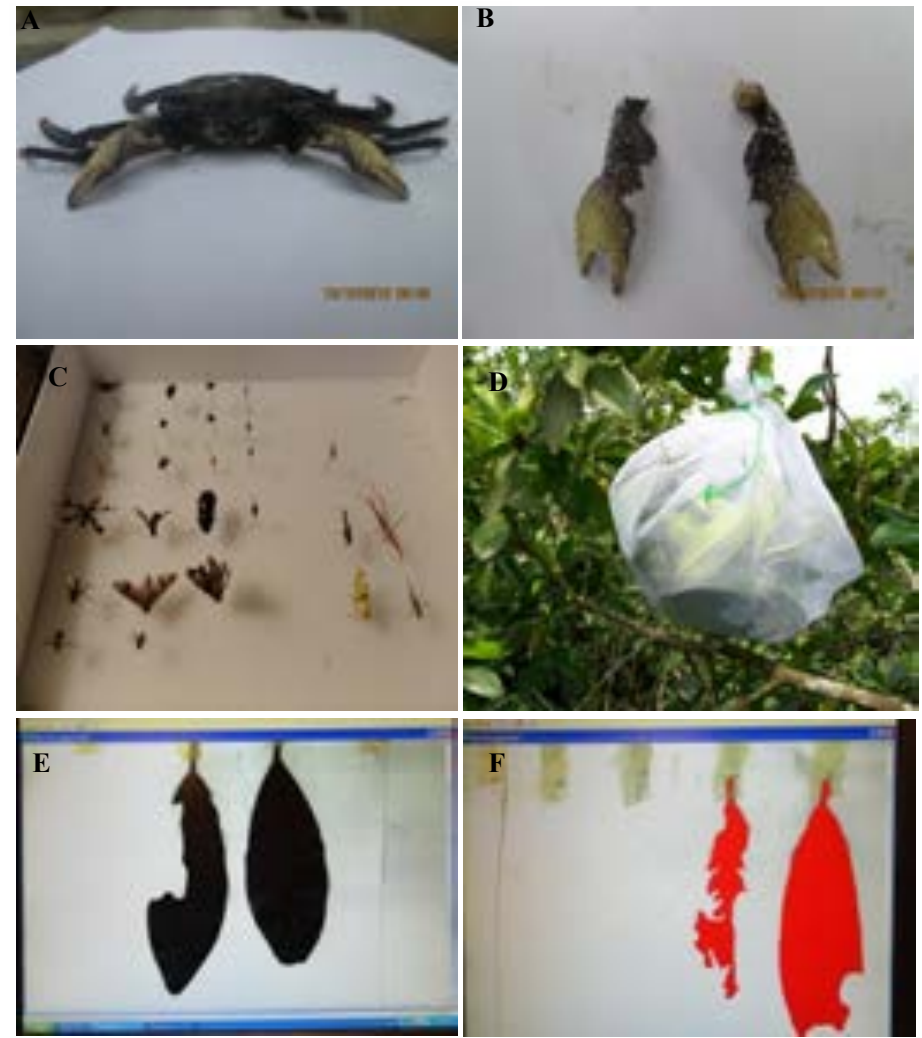

Figure 3: Major mangrove herbivores in the Niger Delta, Nigeria (a) West African Red Mangrove crab (Goniopsis pelii), (b) a pair of chelipeds (c) insect species found in mangrove forest; (d) mesh bag used for exclusion experiment; (e) pre-processed and ( $\mathrm{f}$ ) processed leave sample in Image J software window used to calculate area of leave consumed.

$(24 \mathrm{~cm})$, and has a volume of $19,320 \mathrm{~cm}^{3}$. The containers were one-eighth filled with river water collected in-situ. Green and yellow leaves without marks were plucked from the trees and preserved in black cellophane bags. To determine the total leave consumed and the preference for each leave-type, seven cafeteria experiments were conducted. The 1st experiment estimated the total leaves consumed by the crabs; the 2 nd to 6 th experiments determined the preference based on leaves from highly and lowly polluted plots, while the 7th experiment investigated preference based on color of leaves (i.e., yellow or green). Twenty medium to large adult crabs were later selected from the 40 crabs and placed in the containers. Ten leaves from each plot (i.e., high vs low) was placed in each of the four containers making a total of 40 leaves. The leaves were marked to differentiate those coming from highly and lowly polluted plots. The crabs were starved for 24 hours before the leaves were placed in the containers. At the end of the experiment the leaves were removed, and the area of leave consumed calculated.

\section{Image analysis in Image J}

An image impression of the leaf samples were made with a digital camera (Nikon) at focal length of $30 \mathrm{~cm}$. To confirm the validity of the images a portable handy scan model TSN410 was used to acquire images in line with [8]. The leaf area in pixel was converted to millimeter in image measurement software called Image J for the "pre" and "post" consumption values [37] at a scale of 7.983 pixel $\mathrm{mm}-1$. The pre-consumption estimates were made after reconstructing the leaves with a freehand drawing tool and fill utilities in Image J. In addition, the leaves were visually inspected to calculate total herbivory by determining the number of holes made on the leaves. The type of herbivore bite marks made on the leaves were assessed and assigned count numbers following the example [36]. The rate of herbivory for the exclusion experiment was calculated by computer estimation of area of leave consumed in Image J. The leave area eaten $\left(\mathrm{LA}_{\text {eaten }}\right)$ was calculated by subtracting leave area after herbivory $\left(\mathrm{LA}_{\text {after }}\right)$ from original leaf area before herbivory $\left(\mathrm{LA}_{\text {before }}\right)$.

\section{Statistical analysis}

Herbivory estimations were done based on highly vs. lowly polluted plot, excluded vs. control and up vs. down branches of mangrove trees. We used ANOVA to analyze leaf area consumed as a function of pollution, exclusion and branch for the six months, one year and two years samples (Table 2). A Tukey HSD post hoc test was conducted for all data. All analyses were performed in R statistical environment, v. 3.0.1 [38].

For the cafeteria experiment, we interpreted the leaves with and without bite marks as response variables, and pollution levels as predictor variable [39]. Contingency tables were made for leaves with bite marks ("yes") or leaves without bite marks ("no"). Since the explanatory variables were binary, chi-square test was used to analyze the results. The outcome of "bite marks" versus "no bite marks" i.e., yes or no respectively was compared with a paired sample t-test [40].

\section{RESULT AND DISCUSION}

\section{Exclusion experiment}

We collected a total of 453 leave samples for two years from the field-based herbivory analysis as follows: Six month (160 leaves), one year (184 leaves) and two years (169 leaves). Our study revealed that hydrocarbon pollution significantly influenced leaf consumption by herbivores in the six months $(\mathrm{F}=3.33, \mathrm{P}=0.04)$, one year $(\mathrm{F}=1.90$, $\mathrm{P}=0.02)$ and two-years $(\mathrm{F}=7.58, \mathrm{P}=0.001)$ samples (Figure 4).

There was significant difference in the area of leave consumed by herbivores for both the excluded and control $(\mathrm{F}=32.0, \mathrm{P}<0.0001)$ (Figure 5). But there was no significant difference in the amount of leaves consumed at the up and down branches of the trees $(\mathrm{F}=1.4$, $\mathrm{P}=0.2$ ) (Figure 6). The lower branches of the trees having more leave area consumed especially in the lowly polluted plot. The Turkey's HSD post hoc test, however, indicates that for both the highly and lowly polluted plots the control branch had the highest leave consumption.

There was a significant interaction between pollution and branch for the two year sample (F2, $160=23.20, P<0.0001$, but no interaction between pollution and branch for the six months and one year samples (Table 2).

Based on observations and type of bite marks made on leaves, insects and crabs were the two most dominant herbivores in the mangrove forests. The total herbivory for all the leaves sampled $(n=453)$ in all pollution gradients indicate that $97 \%$ of the leaves were either consumed or incised while 3\% was not consumed and incised. Crabs had a significantly higher number of bite marks 117 (42\%) followed by insects 55 (20\%) and undetermined 50 (18\%) (Figure 7). This gave an overall herbivory of 53\%, 25\% and $22 \%$ 


\begin{tabular}{|c|c|c|c|c|c|c|}
\hline Herbivory period & SOV & DF & SS & MS & $\mathrm{F}$ & $\mathrm{P}$ \\
\hline \multirow[t]{8}{*}{6 Months } & Exclusion vs control & 1 & 1.56 & 1.56 & 1.03 & 0.313 \\
\hline & High vs Low & 2 & 10.17 & 5.08 & 3.33 & $0.038^{*}$ \\
\hline & Up vs. Down & 1 & 0.06 & 0.057 & 0.04 & 0.848 \\
\hline & Exclusion * Pollution & 2 & 2.27 & 1.136 & 0.75 & 0.477 \\
\hline & Treatment * Branch & 1 & 21.74 & 21.74 & 14.26 & $0.0002^{* * *}$ \\
\hline & Pollution vs. Branch & 2 & 4.70 & 2.35 & 1.54 & 0.2170 \\
\hline & Exclusion: Pollution: Branch & 2 & 7.24 & 3.62 & 2.37 & 0.0964 \\
\hline & Residuals & 160 & 244.01 & 1.53 & & \\
\hline \multirow[t]{4}{*}{1 Year } & High vs Low & 2 & 6.05 & 3.026 & 1.90 & $0.0153^{*}$ \\
\hline & Up vs. Down & 1 & 0.67 & 0.671 & 0.42 & 0.517 \\
\hline & Pollution: Branch & 2 & 2.17 & 1.086 & 0.68 & 0.507 \\
\hline & Residuals & 184 & 293.28 & 1.594 & & \\
\hline \multirow[t]{8}{*}{2 year } & Exclusion vs. control & 1 & 0.28 & 0.277 & 0.44 & 0.509 \\
\hline & High vs Low & 1 & 4.80 & 4.796 & 7.58 & $0.007^{* *}$ \\
\hline & Up vs. Down & 1 & 10.88 & 10.88 & 17.20 & $0.0001^{* * *}$ \\
\hline & Pollution: Treatment & 1 & 0.70 & 0.700 & 1.11 & 0.294 \\
\hline & Pollution: Branch & 1 & 14.68 & 14.678 & 23.20 & $0.0001^{* * *}$ \\
\hline & Branch: Treatment & 1 & 2.05 & 2.049 & 3.24 & 0.074 \\
\hline & Treatment: Pollution: Branch & 1 & 0.59 & 0.589 & 0.93 & 0.336 \\
\hline & Residuals & 169 & 106.92 & 1.633 & & \\
\hline
\end{tabular}

\section{${ }^{*}$ Significant}

Table 2: Summary of statistical analysis for exclusion experiment conducted in highly and lowly polluted plots in the mangrove forest (Rhizophora racemosa) in the Niger Delta, Nigeria.

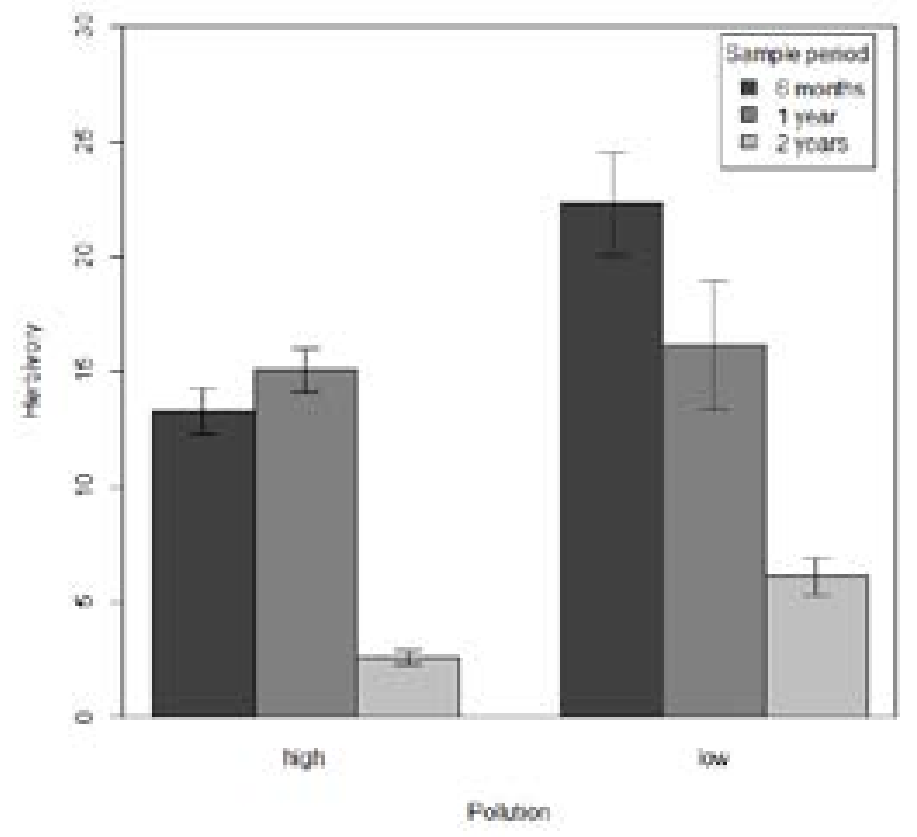

Figure 4: Amount of herbivory in highly and lowly polluted plots for the sample period of 6 months, 1 year and 2 years in the mangrove forest of the Niger Delta, Nigeria.

for crabs, insect and undetermined respectively. The dominant insect species recorded at both treatments were ants, followed by grasshoppers and spiders.

\section{Crab cafeteria experiment}

In the $1^{\text {st }}$ experiment more area was consumed in leaves from highly polluted plot $\left(806.38 \mathrm{~cm}^{2}\right)$ than leaves from lowly polluted plot $\left(160.57 \mathrm{~cm}^{2}\right)$. There was a significant difference in the number of

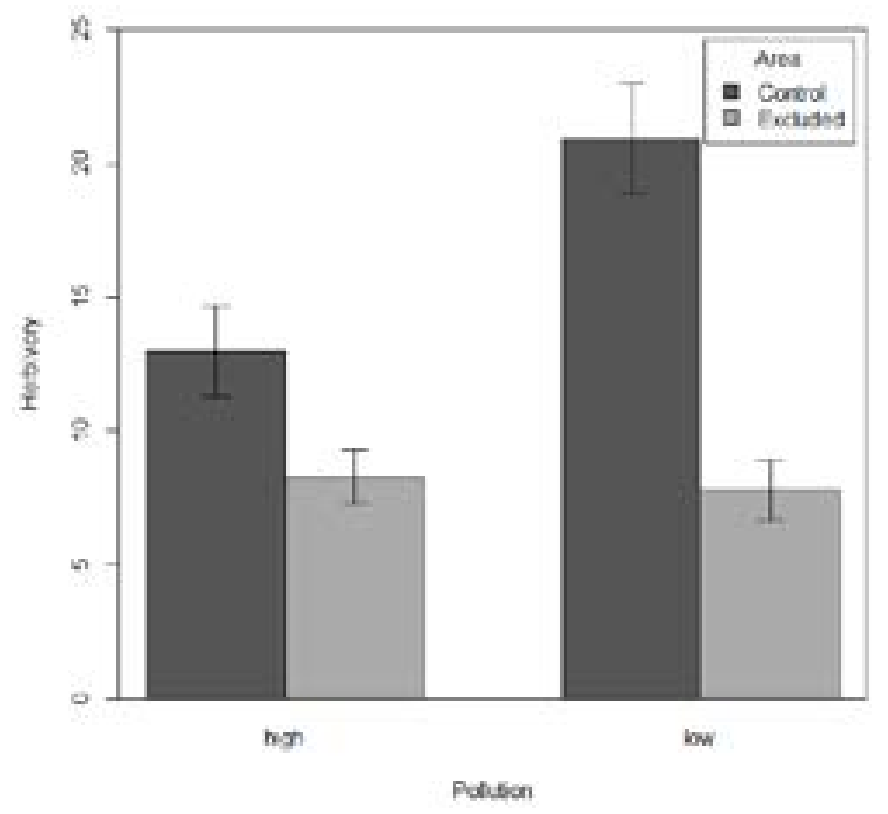

Figure 5: Amount of herbivory in highly and lowly polluted plots for excluded and control branches in the mangrove forest of the Niger Delta, Nigeria. Vertical lines show $\pm 95 \%$ confidence interval.

incisions made on leaves from highly and lowly polluted treatments $(\mathrm{df}=1, \mathrm{P}=0.01)$. This means crabs made more incisions on leaves from lowly polluted plot (68) than leaves from highly polluted plot (64), but practically consumed more leaves from highly $(4,521.69$ $\left.\mathrm{cm}^{2}\right)$ than leaves from lowly $\left(2,769.83 \mathrm{~cm}^{2}\right)$ polluted plot when the area of leaves consumed from $1^{\text {st }}$ to $7^{\text {th }}$ experiment were added together.

Conversely, in terms of color, there was no significant difference $(\mathrm{df}=1, \mathrm{P}=0.14)$ in the number of incisions made on leaves. Crabs 


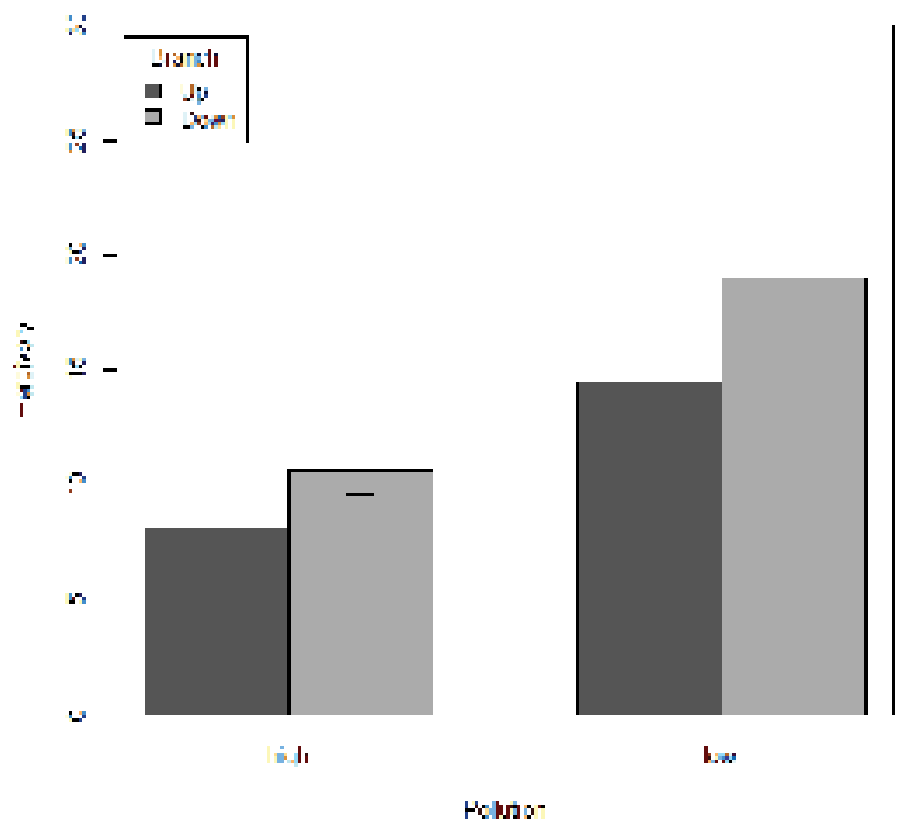

Figure 6: Amount of herbivory in highly and lowly polluted plots for up and low branches in the mangrove forest of the Niger Delta, Nigeria. Vertical lines show $\pm 95 \%$ confidence interval.

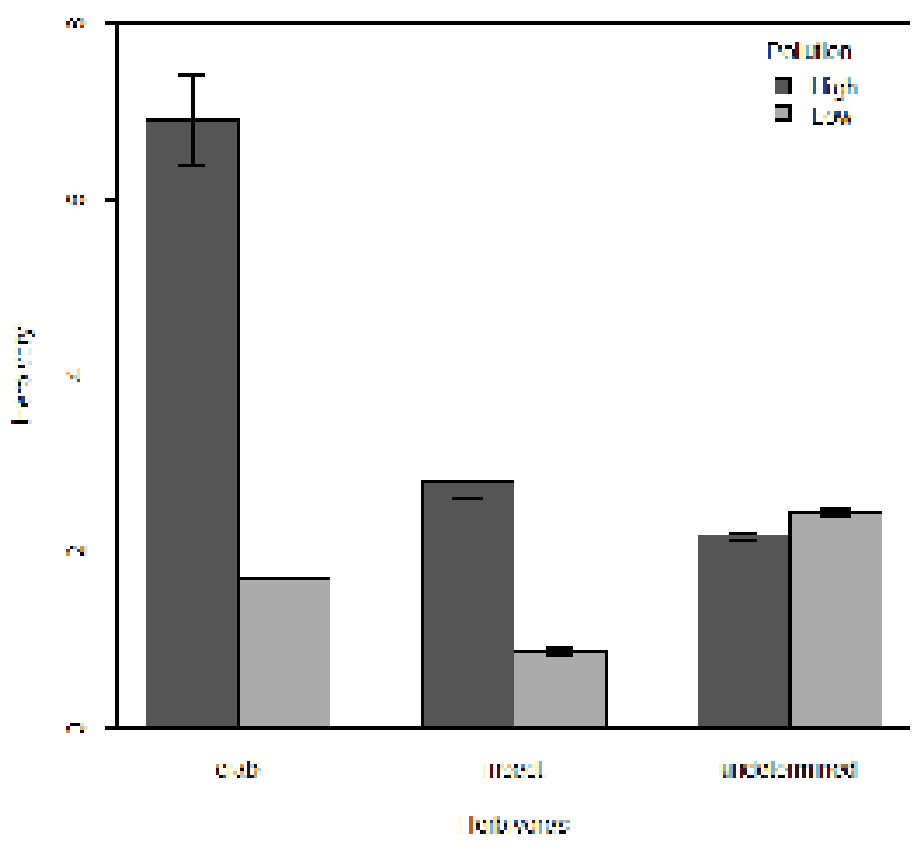

Figure 7: Graph of herbivory by different herbivores in highly and lowly polluted plot in mangroves forest in the Niger River Delta, Nigeria. Vertical lines show \pm standard error of the mean.

made 9 marks on yellow leaves and 13 marks on green leaves. But they practically consumed more area in green leaves $(1,739.89$ $\mathrm{cm}^{3}$ ) than yellow leaves $\left(209.53 \mathrm{~cm}^{3}\right)$. Furthermore, there was a significant difference between the pre and post leave consumption (t-test: $\mathrm{t} 187=5.12, \mathrm{P}=0.0001)$.

\section{DISCUSSION}

Results from this study showed that hydrocarbon pollution directly influenced the consumption of mangrove leaves by herbivores. The field study was conducted in an area that has been impacted by oil and gas exploration activities for decades. Higher amount of leaves were consumed from lowly than highly polluted plots from both the field and laboratory-based experiments. Palatability of leave influenced consumption [41,42]. Other studies had shown that the presence of chemicals in leaves can deter herbivore feeding [8]. This is in line with the hypothesis that hydrocarbon pollution will deter herbivory of mangrove leaves. In contrast, studies have shown that there are no correlations between heavy metals in sediments and in mangrove leaves [43]. Although, previous studies [20] had earlier revealed that hydrocarbons can be transferred from the soil through the root to mangrove leaves. However, another study had indicated that soil nutrients improve plant quality trait, and determines herbivore preference for leaves of mangroves on polluted soils [44].

Incisions made on mangrove leaves do not mean consumption because crabs have the habit of shredding mangrove leaves without consuming them. Bite marks without actual consumption could be a "taste test" by the crabs to determine the palatability of the leaves [41]. Leave-shredding is a common behavior exhibited by mangrove crabs [45]. Shredded leaves provide raw materials for decomposers [45], which helps to drive the process of nutrient cycling [27]. Decomposed leaves are more palatable for crabs because of the reduced tannin content of the leaves $[8,46]$.

During the field work it was observed that crowding of small to medium sized crabs at the lower branches of mangrove trees may have contributed to higher herbivory at lower branches. This means large population of crabs at a particular region of the mangrove trees can lead to increased feeding on the leaves. Similarly, tidal movement can also influence foraging habit of crabs. This is because it was observed that during high tide, crabs climb the lower parts of the tree from the ground to forage while, during low tide crabs come to the ground to feed. During oil spillages crabs forage more on the trees than on the ground. The crabs also avoided trees with dead and yellow leaves but crowded trees with green leaves. This behaviour was observed during the lab-based study, which showed that crabs made more incisions on yellow leaves, but consumed more green leaves when given the choice of both types of leaves. This finding is supported by previous works $[16,47]$ who found out that crabs preferred yellow leaves than green leaves.

The feeding dominance of crabs in our study system indicates that mangrove forest is their major habitat and enhances their survival. Although insects are more diverse and have higher population size in the mangrove forest, they still cause little damage as compared to the crabs. The territorial behaviour and the formation of feeding guilds by crabs contribute to the differential feeding pattern on leaves at different sections of mangrove trees. The big crabs colonized the upper branches while the small and medium-sized crabs occupied the lower branches. Crabs play key role in mangrove ecosystem by indirectly providing food for other organisms through their leaf-shredding and propagule dispersal behaviour, which has consequences in food redistribution in the mangrove ecosystem.

Additional studies are needed to clarify whether other factors such as nutrients level and chlorophyll content are responsible for higher herbivory in lowly polluted plot.

\section{CONCLUSION}

The result shows that herbivory was influenced by soil hydrocarbon pollution, which led to an increased consumption of mangrove leaves in lowly polluted plot. Green leaves had better appeal for 
crabs, this is why more green leaves were consumed than yellow leaves. Similarly, higher population of crabs was found on trees with green leaves than trees with yellow leaves. The outcome of this study indicates that crabs were the top herbivores of mangrove forest and survive by feeding on the leaves.

\section{ACKNOWLEDGEMENTS}

We thank Chimezie and Sokari for assistance with sample collections. The project was supported by Idea Wild, a Saint Louis University Brennan Summer Fellowship and the Educational trust fund by the University of Port Harcourt, Nigeria.

\section{REFERENCES}

1. Bowlman WD, Hacker SD, Cain ML. Ecology. 4th edn. Sinauer Associates Inc., Massachusetts, USA. 2017;pp:15-16.

2. Taketani RG, Franco NO, Rosado AS, Van Elsas JD. Microbial community response to a simulated spill in mangrove sediments. J Microbiol. 2010;48:7-15.

3. Marquis RL. Leaf herbivores decrease fitness of a tropical plant. Sci. 1984;226:537-539.

4. Stowe KA, Marquis RJ, Hochwender CG, Simms EL. The evolutionary ecology of tolerance to consumer damage. Ann Rev Ecol Sys. 2000;31:565-595.

5. Dyer LA, Singer MS, Lill JT, Stireman JO, Gentry GL, Marquis RJ, et al. Host specificity of Lepidoptera in tropical and temperate forests. Nature. 2007;448:696-699.

6. Onuf C, Teal J, Valiela I. The interactions of nutrients, plant growth and herbivory in a mangrove ecosystem. Ecology. 1997; 58:514-526.

7. Murphy DH. The natural history of insect herbivory on mangrove trees in and near Singapore. Raffles Bull Zool. 1990;38:119-203.

8. Tong YF, Lee SY, Morton B. The herbivore assemblage, herbivory and leaf chemistry of the mangrove Kandelia obovata in two contrasting forests in Hong Kong. Wetlands Ecol Manag. 2006;14:39-52.

9. Nielson MG. Distribution of the ant.Hymenoptera:Formicidae; fauna in the canopy of the mangrove tree Sonneratia alba. J Smith in Northern Australia. Austr J Entomol. 2000;39:275-279.

10. Offenberg J, Nielsen MG, Macintosh DJ, Havanon S, Arksonkoae S. Evidence that insect herbivores are deterred by ant pheromones. Proc R Soc Lond Ser B. 2004;271:S433-S435.

11. Lee SY. Herbivory as an ecological process in a Kandelia candel mangal in Hong Kong. J Trop Ecology. 1991;7:337-348.

12. Mothershead K, Marquis RJ. Fitness impacts of herbivory through indirect effects on plant-pollinator interactions in Oenothera macrocarpa. Ecology. 2000;81:30-40.

13. Smith TJ. Effects of seed predators and light level on the distribution of Avicennia marina Forsk in tropical tidal forests. Estuar Coast Shelf Sci. 1987;25:43-51.

14. Vergara-Filho WL, Alves JRP, Maciel NC. Diversity and distribution of crabs.Crustacea, Decapoda, Brachyura; in mangroves of Guanabara Bay, Rio de Janeiro, Brazil. In:Kjerfve B, Lacerda LD, Diop S, et al.. eds.; Mangrove Ecosystem Studies in Latin America and Africa, UNESCO, Paris. 1997:155-162.

15. Cannicci S, Ritossa S, Ruwa RK, Vannini M. Tree fidelity and hole fidelity in the tree cab Sesarma leptosome.Decapoda:Grapsidae;. J Exp Mar Biol Ecol. 1996;196:299-311.

16. Steinke TD, Rajh A, Holland AJ. The feeding behavior of the red mangrove crab Sesarma meinertii De Man, 1887. Crustacea:Decapoda:Grapsidae; and its effect on the degradation of mangrove leaf litter. Afr J Mar Sci. 1993;13:151-160.

17. Conde JE, Diaz H. Extension of the stunting range in ovigerous females of the mangrove crab Aratus pisonii.H. Milne Edwards, 1837; Decapoda:Brachyura:Grapsidae;. Crustaceana. 1992;62:319-322.

18. Conde JE, Alarcon C, Flores S, Diaz H. Nitrogen and tannins in mangrove leaves might explain interpopulation variations in the crabs Aratus pisonii. Acta Cintifica de Venezuela. 1995;46:303-304.

19. White TCR. The abundance of invertebrate herbivores in relation to the availability of nitrogen in stressed food plants. Oecol. 1984;63:90-105.

20. Getter CD, Ballou TG, Koons CB. Effects of dispersed oil on mangroves synthesis of a seven-year study. Mar Pollut Bull. 1985;16:318-324.

21. Mackey AP, Smail G. The decomposition of mangrove litter in a subtropical mangrove forest. Hydrobiol. 1996;332:93-98.

22. Twilley RR. Mangrove wetland. Ecosystems Mangrove Wetlands, Encyclopedia of Ecology. 2008;pp:2198-2208.

23. Kathiresan K, Bingham BL. Biology of mangrove ecosystems. Adv Mar Biol. 2001;40:81-251.

24. Ballou TG, Dodge RE, Hess SC, Knap AH, Sleeter TD. Effects of a dispersed and undispersed crude oil on mangroves, sea grasses and corals. API 4460. American Petroleum Institute, Washington DC, USA, 1987.

25. Gobo AE. Micrometeorological studies for bonny environment. Afr J Environ Stud. 2001;2:42-46.

26. Numbere AO. Impact of hydrocarbon pollution on the mangrove ecosystem of the Niger River Delta, Nigeria. PhD Dissertation, Saint Louis University, Saint Louis, Missouri, USA 2014.

27. Numbere AO, Camilo GR. Mangrove leaf litter decomposition under mangrove forest stands with different levels of pollution in the Niger River Delta, Nigeria. Afr J Ecol. 2017;55:162-167.

28. Ukpong IE. Vegetation and its relation to soil nutrient and salinity in the Calabar mangrove swamp, Nigeria. Mangroves and Salt Marshes. 1997;1:211-218.

29. Numbere AO, Camilo GR. Structural characteristics, above ground biomass and productivity of mangrove forest situated in areas with different levels of pollution in the Niger Delta, Nigeria. Afr J Ecol. 2018;56:917-927.

30. Amadi AA. A comparative ecology of estuaries in Nigeria. Hydrobiol. 1990;208:27-28.

31. NDES. The Niger Delta Environmental Survey.Phase 1;, environmental socio-economic characteristics. Lagos-Nigeria:Environmental Resources Managers Limited 1997.

32. Saenger P, Bellan MF. The mangrove vegetation of the Atlantic coast of Africa:A Review. Southern Cross University, ePublication @SCU 6691995.

33. Wakley A, Black IA. An Examination of the Degtjareff Method for Determining Soil Organic Matter and Proposed Modification of the Chromic Acid Titration Method. Soil Sci. 1934;3:29-38.

34. Watanabe FS, Olsen SR. Test of an Ascobic Acid Method for Determining $\mathrm{P}$ in water and NaHCO Extracts from Soils. Soil Sci Amer Pro. 1965;29:77-678.

35. Young TP, Okello BD. Relaxation of an induced defense after exclusion of herbivores:Spines on Acacia drepanolobium. Oecol. 1998;115:508-513.

36. Lau JA, McCall AC, Davies KF, Mckay JK, Wright JM. Herbivores and edaphic factors constrain the realized niche of a native plant. Ecology. 2008;89:754-762. 
37. Piovia-Scott J. Plant phenotype influences the effect of ant mutualists on a polymorphic mangrove. J Ecol. 2011;99:327-334.

38. R Development Core Team. R:A Language and Environment for Statistical Computing. R Foundation for Statistical Computing, Vienna, Austria 2013.

39. Quinn GP, Keough KJ. Experimental design and data analysis for biologists. Cambridge University Press, London, UK 2002.

40. Pennings SC, Carefoot TH, Siska EL, Chase ME, Page TA. Feeding preferences of a generalist salt marsh crab:relative importance of multiple plant traits. Ecology. 1998;79:1968-1979.

41. Soto R. Nutrient concentration and retranslocation in coastal vegetation and mangroves from the Pacific coast of Costa Rica. Brenesia. 1992;37:33-50.
42. Erickson AA, Ball SS, Dawes CJ. Does mangrove leaf chemistry explain crab herbivory. Biotropica. 2004;36:333-343.

43. Sadiq M, Zaidi TH. Sediment composition and metal concentrations in mangrove leaves from the Saudi coast of the Arabian Gulf. Sci Total Environ. 1994;155:1-8.

44. Boege K. Herbivore attack in Casearia nitida influenced by plant ontogenetic variation in foliage quality and plant architecture. Oecol. 2005;143:117-125.

45. Longonje SN, Raffaelli D. Feeding ecology of mangrove crabs in Cameroon. Merit Res J Environ Sci Toxicol. 2013;1:099-108.

46. Komiyama A, Ong JE, Poungparn S. Allometry, biomass, and productivity of mangrove forests:A review. Aqua Bot. 2008; 89:128-137.

47. Micheli F, Gherardi F, Vannini M. Feeding and burrowing ecology of two East African mangrove crabs. Mar Biol. 1991; 111:247-254. 